\title{
X-linked intellectual disability, Najm type
}

INSERM

\section{Source}

INSERM. (1999). Orphanet: an online rare disease and orphan drug data base. $\underline{X \text {-linked }}$ intellectual disability, Najm type. ORPHA:163937

Najm type $X$-linked intellectual deficit is a rare cerebellar dysgenesis syndrome characterized by variable clinical manifestations rang ing from mild intellectual deficit with or without congenital nystagmus, to severe cognitive impairment associated with cerebellar and pontine hypoplasia/atrophy and abnormalities of cortical development. 